\title{
Ka-band Coplanar Low-Noise Amplifier Design with Power PHEMTs
}

\author{
Sabine Long ${ }^{1}$, Laurent Escotte ${ }^{1}$, Jacques Graffeuil ${ }^{1}$, Philippe Fellon ${ }^{2}$ and Daniel Roques ${ }^{3}$ \\ ${ }^{1}$ LAAS CNRS et Université Paul Sabatier, 7 Av. du Colonel Roche, 31077 Toulouse cedex 4, France \\ e-mail : escotte@laas.fr, phone : 33 (0)5 613364 56, fax : 33 (0) 561336969 \\ ${ }^{2}$ United Monolithic Semiconductors, 91041 Orsay cedex, France \\ ${ }^{3}$ Alcatel Space, 26 Av. J.F. Champollion, 31037 Toulouse cedex, France
}

\begin{abstract}
The design of a coplanar low-noise amplifier (LNA) is presented in this paper. Pseudomorphic high electron mobility transistors (PHEMTs), optimized for power applications, are used in order to evaluate the potentiality of this technology for mixed-mode applications. The three stages amplifier noise figure is lower than $2.6 \mathrm{~dB}$ on the $27-31 \mathrm{GHz}$ frequency band with a $20 \mathrm{~dB}$ power gain.
\end{abstract}

\section{INTRODUCTION}

A cost reduction of circuit design and production for mixed-mode (low noise / power) applications could be achieved using only one kind of component. The number of component modeling steps is then reduced and the low-noise and power circuits are fabricated at the same time. This cost saving can further be improved by using a flip-chip assembly which achieves simultaneously the mechanical and electrical link between the chip and its mounting substrate. Moreover, flip-chip report is automatizable and compact [1] and thermal bumps implemented on the source pads of the transistors reduce the thermal resistance of the devices [2]. However, it makes necessary the use of a coplanar technology in order to decrease the carrier substrate detrimental influence on the circuit behavior [3]. Coplanar LNA have been yet realized in V and W-band [4]-[5], but this technology is not currently used in Ka-band.

We present in this paper the design of a Ka-band coplanar low-noise amplifier (LNA). This circuit is based on pseudomorphic high electron mobility transistors (PHEMT) optimized for power applications and fits the prerequisites of flip-chip assembly. The transistor noise characteristics are described in the second section and compared with those of a more classical low-noise PHEMT. The third section is dedicated to the circuit design and the simulation results are given in section four. Experimental results are reported in the last section.

\section{DeVICE CHARACTERISTICS}

The $0.25 \mu \mathrm{m}$ gate length GaAs-power transistors are AlGaAs/InGaAs PHEMTs of the United Monolithic Semiconductors (UMS) foundry and feature a doubleheterojunction (DH). The second heterojunction, located under the channel, improves the power performances of the transistor. It allows a higher number of free electrons to travel along the channel, and then, provides a higher maximal drain current, $I_{d \max }$. The device also features a double-recessed gate which increases the breakdown voltage [6].

The high frequency noise of these components is compared to those of conventional low-noise singleheterojunction PHEMTs (SH-PHEMT) elsewhere [6]. The noise parameters of these two kinds of transistors are very close, as shown in Fig. 1, even if the technologies are optimized for different applications. The minimum noise figure $F_{\text {min }}$ features a $1.6 \mathrm{~dB}$ minimum at $30 \mathrm{GHz}$ for a drain current equal to 75 $\mathrm{mA} / \mathrm{mm}$.

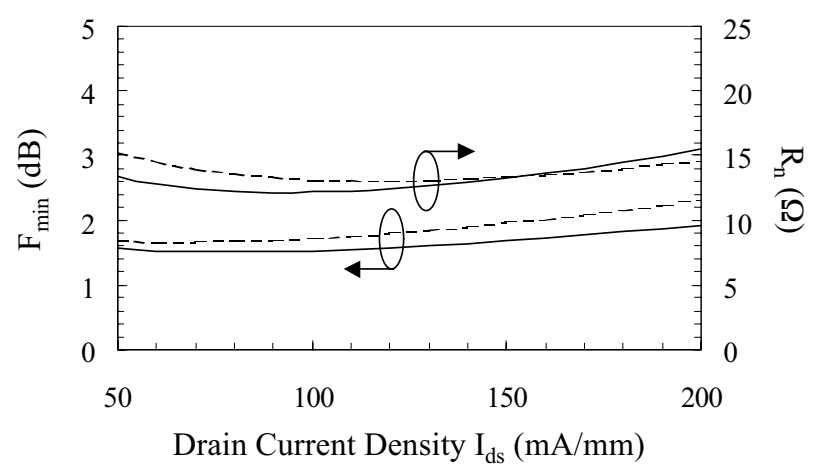

Fig. 1. Minimum noise figure $\mathrm{F}_{\min }$ and equivalent noise resistance $R_{n}$ variations against drain current density at $30 \mathrm{GHz}$ and $\mathrm{V}_{\mathrm{ds}}=2 \mathrm{~V}$. - - -: DH-PHEMT; —: $\mathrm{SH}-$ PHEMT.

The small-signal and noise model of the power transistors are extracted from scattering and noise parameter measurements carried out up to $40 \mathrm{GHz}$. The noise parameters are measured using a Ka-band sourcepull test bench developed in our laboratory [7]. This model is scalable in terms of gate geometry (width and number of gate fingers) and drain current $\mathrm{I}_{\mathrm{d} s}$.

\section{Circuit Design}

The objective was to design a $20 \mathrm{~dB}$ gain MMIC amplifier that covers the $27-31 \mathrm{GHz}$ frequency band. A three-stage circuit topology was chosen to achieve the targeted specifications. The gate geometry and bias conditions of the two first stages are selected in order to 
minimize the noise figure. To this end, each of the four noise parameters and the associated gain are considered. We select a component having a minimum noise figure together with an equivalent noise resistance $R_{n}$ as low as possible. This last feature reduces the noise figure increase in case of a minor noise mismatching.

The variations of $F_{\min }$ and $R_{n}$ against gate geometry are reported in Fig. 2 at $30 \mathrm{GHz}$ and $\mathrm{I}_{\mathrm{ds}}=100 \mathrm{~mA} / \mathrm{mm}$.
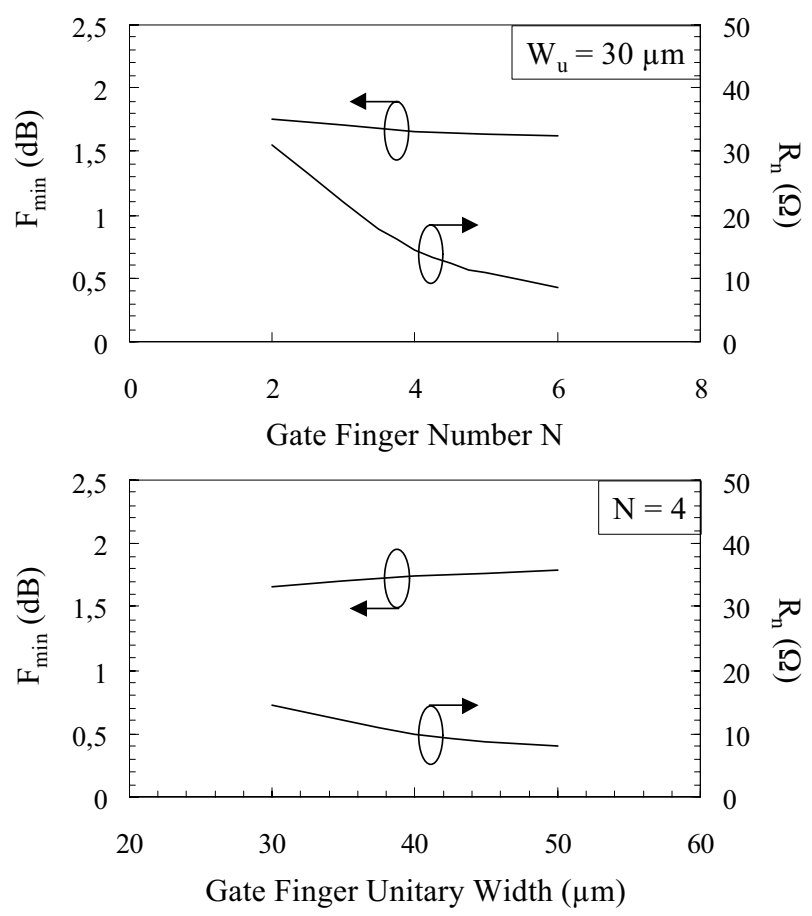

Fig. 2. Minimum noise figure $F_{\min }$ and equivalent noise resistance $R_{n}$ variations against gate geometry at $30 \mathrm{GHz}$ and $\mathrm{I}_{\mathrm{ds}}=100 \mathrm{~mA} / \mathrm{mm}$.

An increase of the gate number $\mathrm{N}$ considerably decreases $R_{n}$ and, to a lesser extent, $F_{\min }$. A decrease of the gate finger width $W_{u}$ decreases $F_{\text {min }}$ and slightly increases $R_{n}$. The associated gain is also higher for the smallest devices. Finally, a component featuring a high $\mathrm{N}(=6)$ and small $\mathrm{W}_{\mathrm{u}}(=30 \mu \mathrm{m})$ is selected.

The choice of drain current value results from a tradeoff between $F_{\text {min }}$ and $R_{n}$. As shown in Fig. 1, the minimum of $F_{\min }$ is obtained for a drain current equal to $75 \mathrm{~mA} / \mathrm{mm}$ and the $\mathrm{R}_{\mathrm{n}}$ minimum for $120 \mathrm{~mA} / \mathrm{mm}$. A drain current equal to $85 \mathrm{~mA} / \mathrm{mm}$ is then chosen for each transistor leading to a total drain current equal to $57 \mathrm{~mA}$ for the LNA.

Finally, the transistor dimensions of the last stage are taken higher than those of the two first stages $(6 \times 50 \mu \mathrm{m}$ instead of $6 \times 30 \mu \mathrm{m})$ in order to improve the linearity of the amplifier. The voltage bias conditions of the three stages are then identical $\left(\mathrm{V}_{\mathrm{d}}=2.2 \mathrm{~V}\right.$ and $\left.\mathrm{V}_{\mathrm{g}}=-0.3 \mathrm{~V}\right)$.

The circuit design was performed using ADS (Agilent $^{\circledR}$ ) and COPLAN (IMST) softwares. The passive elements are simulated with COPLAN using a physical description (height and width of the different layers).

The layout and the schematic diagram of the Ka-band MMIC LNA are shown in Fig. 3.

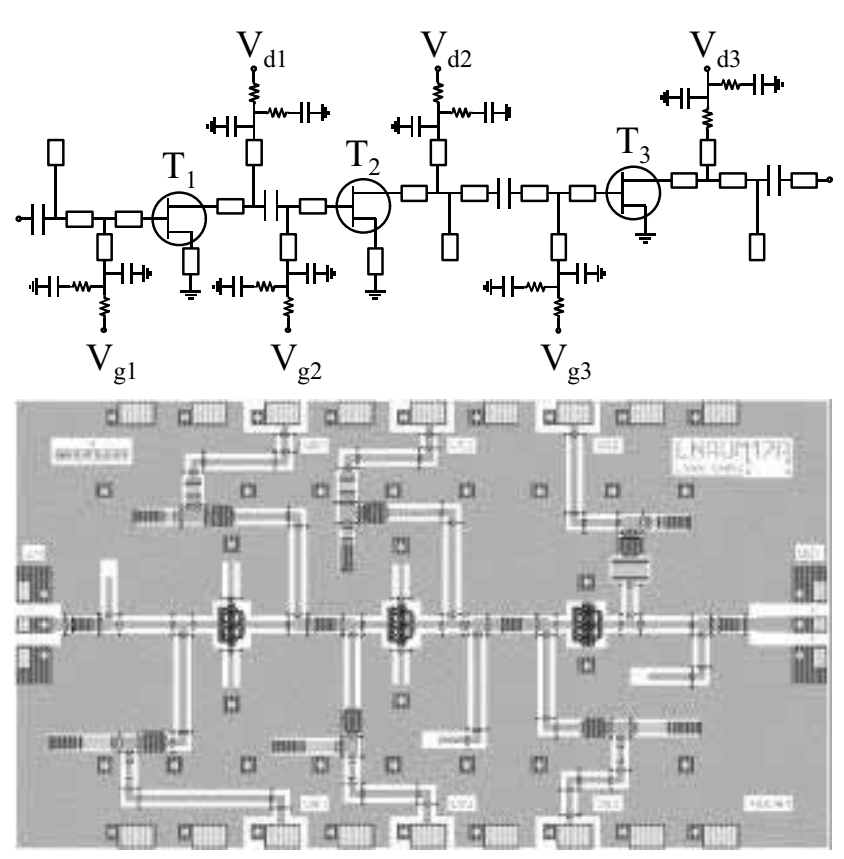

Fig. 3. Topology and layout of the coplanar low-noise amplifier $\left(3.5 \times 2 \mathrm{~mm}^{2}\right)$.

Inductive short-circuited lines connected to the source electrodes of the two first transistors are used to ensure stability and to bring together the optimum noise reflection coefficient $\Gamma_{\text {opt }}$ and the conjugate of the input reflection coefficient $\left(\mathrm{S}_{11} *\right)$. The third stage is stabilized using a shunt TaN resistance located on the drain.

Matching networks are based on coplanar transmission lines. Air-bridges are used at each discontinuity in order to suppress any undesired slotline mode on the coplanar waveguide (CPW). RC networks are added in the bias circuits in order to avoid lowfrequency oscillations. Inter-stage MIM capacitors are used for DC-blocking.

Cylindrical bumps, with $30 \mu \mathrm{m}$ diameter and height, are laid out on the circuit to allow the further flip-chip assembly [2]. Microwave and bias probe pads are also added in the layout in order to be able to measure the amplifier before the flip-chip report.

\section{SimUlation RESULtS}

Simulation results are reported in Fig. 4 and Table I. The noise figure $\mathrm{F}_{50}$ is $2.6 \pm 0.2 \mathrm{~dB}$ in the $27-31 \mathrm{GHz}$ frequency range with a $20 \mathrm{~dB}$ gain. The input reflection coefficient is lower than $-10 \mathrm{~dB}$ and the output one is lower than $-20 \mathrm{~dB}$. The stability has been checked by the way of the Rollett factor K for the entire LNA and for each stage.

The predicted noise figure value is not as good as others previously published data [8]-[9]. Nevertheless it must be recalled that our aim was not to design ultra low-noise amplifiers but only to demonstrate the best noise figure as possible using devices optimized for power applications and featuring a $0.25 \mu \mathrm{m}$ gate length. Therefore they cannot afford the same noise performance 
as $0.15 \mu \mathrm{m}$ gate length low-noise transistors. It can also be noted that the coplanar technology used for a further flip-chip assembly features higher losses compared to microstrip technology in this frequency range. For these reasons the predicted noise is attractive and demonstrates that power devices can be used for lownoise amplifier design for mixed-mode applications.
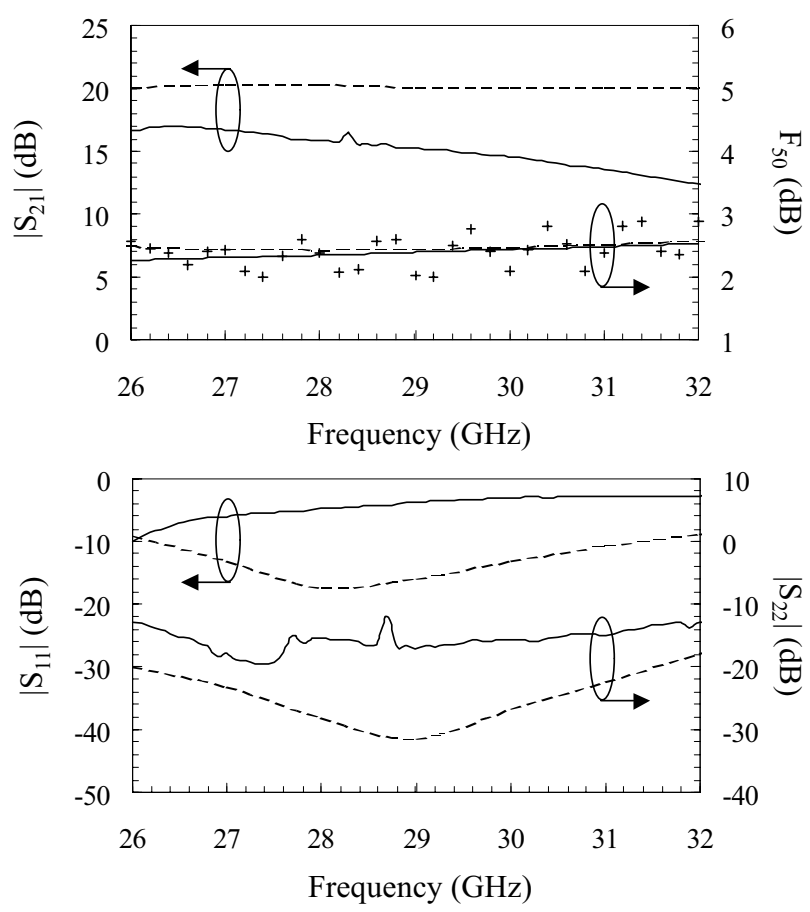

Fig. 4. Simulated and measured characteristics of the LNA at $\mathrm{I}_{\mathrm{d}}=57 \mathrm{~mA}$. $\quad$ - - -: simulation; —: measure.

\section{EXPERIMENTAL RESULTS}

Fig. 4 shows the measured characteristics of the LNA. The measured noise figure is in agreement with the calculated values. All the measurement results at $29 \mathrm{GHz}$ are reported in Table $\mathrm{I}$. The noise figure is equal to $2.4 \mathrm{~dB}$ with $15.2 \mathrm{~dB}$ gain. It slowly increases with frequency in the $27-31 \mathrm{GHz}$ frequency range from $2.4 \mathrm{~dB}$ to $2.6 \mathrm{~dB}$. Unfortunately, the measured $\mathrm{S}$ parameters are strongly different than the simulated values. The gain is lower than expected and further decreases versus frequency from $16.7 \mathrm{~dB}$ to $13.6 \mathrm{~dB}$. The measured input reflection coefficient is also higher than the simulated one. Additional measurements below 26 GHz show also a shift in the characteristics $\left(\mathrm{S}_{21}\right.$ and $\left.\mathrm{S}_{11}\right)$ toward lower frequencies.

These unexpected data are related to transistors electrical characteristics that were somewhat different from those found in the foundry design book. This has been verified by measuring a single transistor. The small-signal models of the transistors have then been modified in the simulation files and a retro-simulation was performed. The results are reported in Fig. 5.
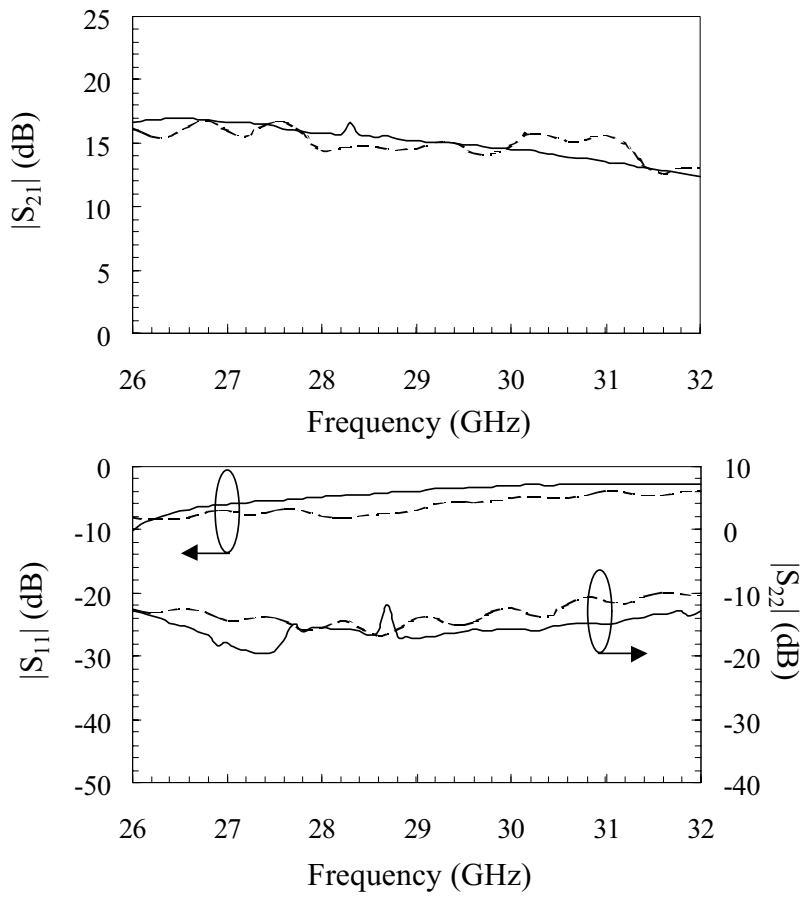

Fig. 5. Retro-simulated with updated transistors data and measured characteristics of the LNA at $\mathrm{I}_{\mathrm{d}}=57 \mathrm{~mA}$. - - -: retro-simulation; - : measurements.

A good agreement is now observed between the retrosimulated values and the experimental results which validate the design technique. The passive elements

\begin{tabular}{|c|c|c|c|}
\hline \multirow{2}{*}{ Parameter } & \multicolumn{2}{|c|}{ Simulation } & \multirow{2}{*}{$\begin{array}{c}\text { Measurement } \\
\text { at 29 GHz }\end{array}$} \\
\cline { 2 - 3 } & $\mathbf{2 7 - 3 1 ~ G H z}$ & at 29 GHz & $15.2 \mathrm{~dB}$ \\
\hline Linear gain & $20 \mathrm{~dB}$ & $20.2 \mathrm{~dB}$ & \\
\hline Gain flatness & $0.3 \mathrm{~dB}$ & & $-3.9 \mathrm{~dB}$ \\
\hline$\left|\mathrm{S}_{11}\right|$ & $<-10 \mathrm{~dB}$ & $-16 \mathrm{~dB}$ & $-17.2 \mathrm{~dB}$ \\
\hline$\left|\mathrm{S}_{22}\right|$ & $<-20 \mathrm{~dB}$ & $-31.3 \mathrm{~dB}$ & Unconditional \\
\hline Stability & Unconditional & Unconditional & $2.4 \mathrm{~dB}$ \\
\hline Noise Figure & $<2.6 \mathrm{~dB}$ & $2.45 \mathrm{~dB}$ & $125 \mathrm{~mW}$ \\
\hline Consumption & $125 \mathrm{~mW}$ & $125 \mathrm{~mW}$ & $11 \mathrm{dBm}$ \\
\hline Output $\mathrm{P}_{1 \mathrm{~dB}}$ & $11 \mathrm{dBm}$ & $11 \mathrm{dBm}$ & \\
\hline
\end{tabular}

TABLE I

SIMULATION AND EXPERIMENTAL RESULTS 
remain unchanged compared to the initial simulations.

\section{CONCLUSION}

A coplanar flip-chip compatible Ka-band low-noise MMIC amplifier design is reported in this paper. A $2.4 \mathrm{~dB}$ noise figure with a $15.2 \mathrm{~dB}$ gain is obtained at $29 \mathrm{GHz}$ although $0.25 \mu \mathrm{m}$ gate length power devices were used. The design of this LNA allows a flip-chip assembly which is well suited for applications in the millimeter-wave range. We conclude that DH-PHEMT devices featuring a double-recessed gate and optimized for power applications can be also used for low-noise applications and show a noise behavior similar to the one of conventional PHEMT. It turns out that using a mixed mode single chip for both low-noise and power amplification in modern transceivers is made possible.

\section{ACKNOWLEDGEMENT}

The authors wish to acknowledge the RNRT (Réseau National de Recherche en Télécommunication) which funded the "OPTIMAL" project (Optimisation en Puissance de Technologies Intégrées Millimétriques pour Amplification Linéaire) that allowed the achievement of this work.

\section{REFERENCES}

[1] C. E. Presley, "FCA: a critical advantage for designers", Advanced Packaging, pp. 38-42, Apr. 1999.

[2] E. Rogeaux, J.P. Fraysse, C. Schaffauser, S. George, D. Pons, P. Fellon, D. Geiger, D. Théron, N. Haese,
S. Verdeyme, R. Quéré, D. Baillargeat, E. Ngoya, S. Long, L. Escotte, "Ka band power pHEMT technology for space power flip-chip assembly", IEEE MTT's Digest, pp. 1895-1898, 2001.

[3] R. Sturdivant, "Reducing the effects of the mounting substrate on the performance of GaAs MMIC flip chips", IEEE MTT's Digest, pp. 1591-1594, 1995.

[4] V. Hoel, S. Boret, B. Grimbert, G. Apercé, S. Bollaert, H. Happy, X. Wallart, A. Cappy, " $94 \mathrm{GHz}$ low noise amplifier on InP in coplanar technology", Microwave Engineering Europe, pp. 51-54, Nov. 1999.

[5] A. Fujihara, E. Mizuki, H. Miyamoto, Y. Makino, K. Yamanoguchi, N. Samoto, "High performance $60-\mathrm{GHz}$ coplanar MMIC LNA using InP heterojunction FETs with AlAs/InAs superlattice layer", IEEE MTT's Digest, pp. 21-24, 2000.

[6] S. Long, L. Escotte, J. Graffeuil, P. Fellon, D. Geiger, D. Pons, "High-frequency noise in pseudomorphic doubleheterojunction high electron mobility transistors", Fluctuation and Noise Lett., vol. 2, n ${ }^{\circ}$, pp. 13-19, Mar. 2002.

[7] S. Long, L. Escotte, J. Graffeuil, F. Brasseau, J.L. Cazaux, "On-wafer noise caracterization of low-noise amplifiers in the Ka-band", IEEE transaction on Instrumentation. and Measurement., to be published in Oct. 2003.

[8] Y. Kwon, D. S. Deakin, E. A. Sovero, J. A. Higgins, "High-performance Ka-band monolithic low-noise amplifiers using 0.2- $\mu \mathrm{m}$ dry-recessed GaAs PHEMT's", IEEE Microwave and Guided Wave Lett., vol. 6, n7, pp. 253-255, Jul. 1996

[9] H. Uchida, S. Takatsu, K. Nakahara, T. Katoh, Y. Itoh, R. Imai, M. Yamamoto, N. Kadowaki, "Ka-band multistage MMIC low-noise amplifier using source inductors with different values for each stage", IEEE Microwave and Guided Wave Lett., vol. 9, n², pp. 71-72, Feb. 1999. 